\title{
Using spatial modelling to develop flood risk and climate adaptation capacity metrics for assessing urban community and critical electricity infrastructure vulnerability
}

\author{
$\underline{\text { R. Espada, Jr. }}{ }^{\text {a }}$, A. Apan ${ }^{\text {a }}$ and K. McDougall ${ }^{a}$ \\ ${ }^{a}$ School of Engineering and Surveying and Australian Centre for Sustainable Catchments, \\ University of Southern Queensland, Queensland, Australia \\ Email: Rudolf.Espada@usq.edu.au
}

\begin{abstract}
The aim of this study was to develop a new spatially-explicit analytical approach for urban flood risk assessment and generation of climate adaptation capacity metrics for vulnerability assessment of critical electricity infrastructure.
\end{abstract}

Using the January 2011 flood in Queensland (Australia) with the core suburbs of Brisbane City as the study area, this study addressed the sufficiency of indicating variables and their suitability for climate risk modelling. A range of geographical variables were analysed using a) high resolution digital elevation modelling and urban morphological characterisation with 3D analysis, b) spatial analysis with fuzzy logic, c) proximity analysis, d) quadrat analysis, e) collect events analysis, f) geospatial autocorrelation techniques with global Moran's I and Anselin Local Moran's I, and g) hot spot analysis. The issue on the sufficiency of indicating variables was addressed using the topological cluster analysis of a 2-dimension self-organising neural network (SONN) structured with 100 neurons and trained by 200 epochs. Furthermore, the suitability of flood risk modelling was addressed by aggregating the indicating variables with weighted overlay and modified fuzzy gamma overlay operations using Bayesian joint conditional probability. Variable weights were assigned to address the limitations of normative (equal weights) and deductive (expert judgment) approaches.

The outputs of the topological cluster analysis showed that 15 out of 22 indicating variables were found sufficient to spatially model the flood risk and climate adaptation capacity metrics. The analyses showed that 214 ha $(9 \%)$ and 255 ha $(11 \%)$ of the study area were very highly impacted by the January 2011 flood as indicated by the very high flood risk metrics and the very low adaptation capacity metrics, respectively. In the electricity network vulnerability assessment, a total count of 72 critical assets (zone supply substations, high voltage switching sites, and pole transformer sites) were found highly vulnerable to flood hazard. The flood damage disrupted electricity supply along $627 \mathrm{~km}$ and $212 \mathrm{~km}$ of transmission lines on the north eastern to south western and south eastern sides of the study area, respectively.

The newly developed spatially-explicit analytical technique, identified in this study as the flood riskadaptation capacity index/metrics-adaptation strategies (FRACIAS) linkage model, will allow the integration of flood risk and climate adaptation assessments which have been treated separately in the past. As technical support to the Queensland Floods Commission of Inquiry (QFCI) recommendations, this study also provides a tool and identifies adaptation strategies to enable urban communities and the power industry to better prepare and mitigate future flood events.

The tool can also be used to assess the physical vulnerability of other critical assets (e.g. water supply, sewerage, communication, stormwater, roads and rails) to flooding.

Keywords: Flood risk assessment, climate adaptation capacity, geospatial autocorrelation, Bayesian joint conditional probability, self-organising neural network 
Espada et al., Using spatial modelling to develop flood risk and climate adaptation capacity metrics for assessing urban community and critical electricity infrastructure vulnerability

\section{INTRODUCTION}

During December 2010 to February 2011, the State of Queensland, in Australia, experienced a series of damaging floods which consequently affected over 200,000 people (McDougall 2012), damaged 29,000 homes and businesses, and killed 37 people (QRA 2011 and QFCI 2012). The damage was expected to cost the Australian economy triple the original estimate of AU\$10 billion (ABC 2011). Specifically, in January 2011, the city of Brisbane had experienced a major flood event inundating more than 14,000 properties (McDougall 2012). As a result of flooding, the government spent almost AU\$7 billion rebuilding and upgrading the State's infrastructures (QFCI 2012, QRA 2011).

Established under the Commission of Inquiry Act 1950, the Queensland Floods Commission of Inquiry (QFCI) was set up to enquire into matters arising out of the 2010/2011 floods (QFCI 2012). The Commission made recommendations for the improvement of preparation and planning and how can flood damage be minimised across essential infrastructures such as electricity, sewerage, storm water, telecommunications, and roads and rails in the future.

In response to these recommendations, the development of flood risk and adaptation capacity metrics was considered in this study. However, developing a comprehensive set of metrics is challenging due to a wide variety of adaptations as well as the dynamic nature of various environmental and socio-economic factors (Szlafsztein 2008). This research problem is further exacerbated by inductive argumentation which particularly pertains to the sufficiency of indicating variables and availability of statistical models in climate risk assessment. When these indicating variables are aggregated with deductive approach (e.g. expert judgment) or by normative approach (e.g. equal weighting), the delivery of robust results is an issue due to subjective judgments in the former case and the multi-dimensionality of variables to different stakeholders in the latter case (Hinkel 2011). This issue is further aggravated by the process of selecting the indicating variables to indicate flood risk and its application to adaptation capacity assessment. This study had devised an ArcGIS-MATLAB algorithm interface in working the self-organising neural network (SONN) to select appropriate indicating variables and aggregate them with weights based on Bayesian probability rule.

Furthermore, the techniques available for critical infrastructure protection modelling are heavily focused on physical interdependency with limited consideration on the geographical interdependency. In a research survey of U.S. and international research on critical infrastructure interdependency modeling conducted by Pederson et al. (2006), modeling and simulation that provide geospatial relationships were excluded in their analysis. Because floods exert spatially correlated disturbances to multiple infrastructures and consequently disrupt services to community, a research question arises as to how geographic interdependency and spatial autocorrelation operate in flood risk assessment. This study also developed a spatially-explicit analytical tool exploring global Moran's I and local Moran's I to simulate geographic interdependency of indicating variables for critical infrastructure and urban community vulnerability assessments.

With these complex issues in mind, this study developed new analytical techniques that will address these research problems and systematically quantify flood risk and climate adaptation capacity metrics of an urban area.

Specifically, the objective of this study was to generate spatially-explicit flood risk and climate adaptation capacity metrics that will aid to address flood risk management and climate resiliency issues of an urban area and critical electricity infrastructure.

\section{THE STUDY AREA}

The study area is located in the core suburbs of Brisbane City, the Queensland's capital in Australia. The City is traversed by the 345kilometer long Brisbane River, which is the longest river in South East Queensland and flows down from Mount Stanley to Moreton Bay (Middelman 2002). Including the Lockyer Creek and Bremer River catchments, around $6,500 \mathrm{~km}^{2}$ (approximately 50\%) of the Brisbane River catchment is below Wivenhoe and Somerset Dams (Robinson 2011).

Brisbane City had an $\$ 85$ billion worth of

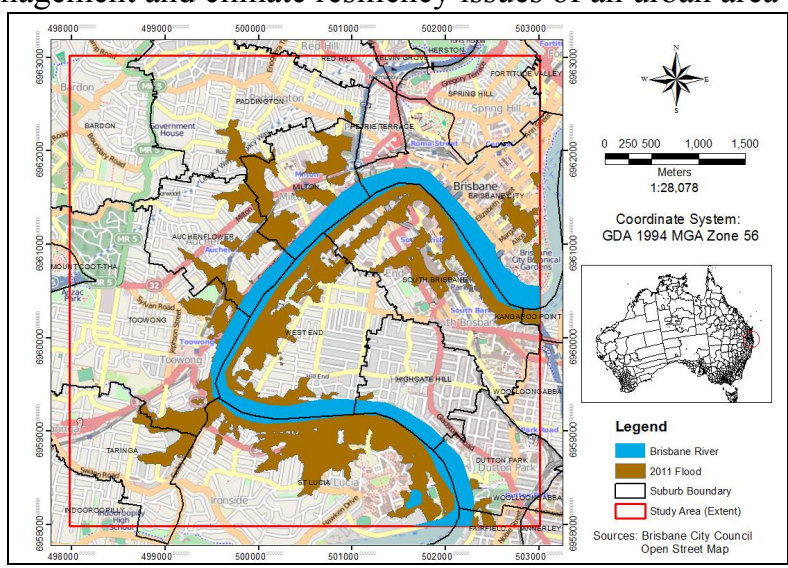

Figure 1. The extent of the study area economy in 2011. However, the City's economic progress together with more than a million estimated residents, had been hampered and devastated recently by 2010/2011 floods. In January 2011, flood waters in 
Espada et al., Using spatial modelling to develop flood risk and climate adaptation capacity metrics for assessing urban community and critical electricity infrastructure vulnerability

Brisbane peaked at 4.46 metres making it one of the worst floods in the city's recorded history with significant damage to transport, infrastructure, and residential properties (Queensland Museum 2011).

Comprising an area of approximately 2,200 ha, the study area includes the 22 central suburbs of Brisbane City as shown in Figure 1.

\section{RESEARCH METHODS}

Figure 2 is the input-process-output (IPO) model used in this study. Highlighted in the figure were data inputs used, processes involved, and the outputs generated from the comprehensive analysis. Under the input component, the flood hazard, vulnerability, and exposure indicators were assessed (Table 1). Under the process component, four main GIS operation challenges were addressed to generate the flood risk and adaptation capacity metrics: 1) transformation and standardisation of indicating variables, 2) topological cluster analysis, 3) quantification of

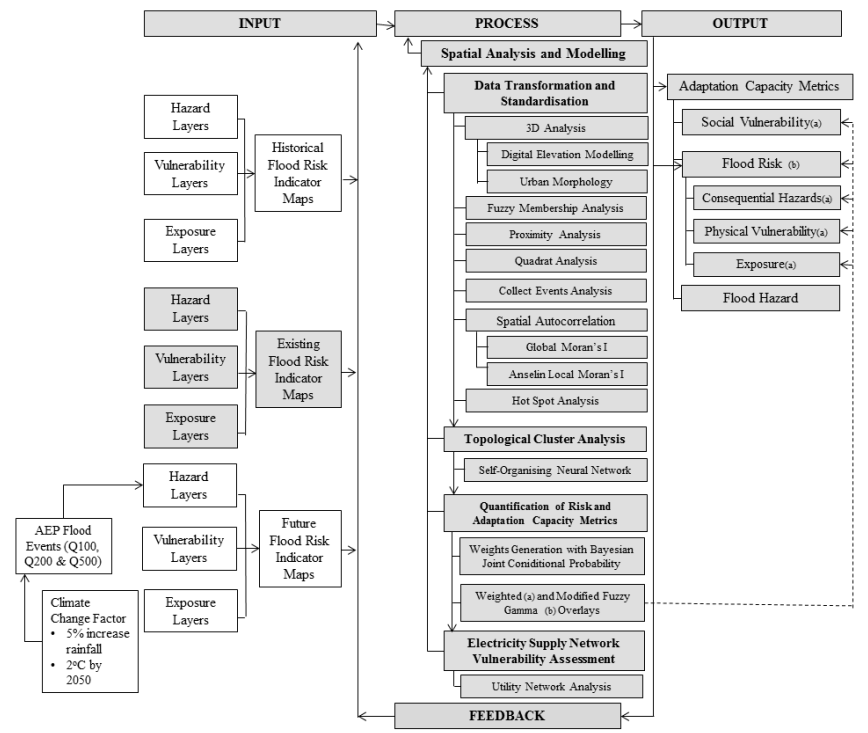

Figure 2. The input-process-output (IPO) model used in the study flood risk and adaptation capacity metrics, and (4) electricity network analysis.

The final outputs (i.e. flood risk and adaptation capacity metrics) were then applied in assessing the vulnerability of urban community in general and critical electricity infrastructure in particular.

\section{FLOOD RISK AND ADAPTATION CAPACITY MODELLING}

\subsection{Key Concepts and Data Inputs}

Mathematically, risk can be expressed in the following forms (Mirfenderesk and Corkill 2009; Downing 2002; Hughey and Bell 2010):

$$
\begin{aligned}
& \text { Risk }=\text { Hazard } * \text { Vulnerability } * \text { Exposure } \\
& \text { Risk }=\text { Hazard }+ \text { Vulnerability } \\
& \text { Risk }=\text { Hazard }+ \text { Vulnerability }- \text { Adaptation Capacity }
\end{aligned}
$$

The UNISDR (2009) defined hazard as a "dangerous phenomenon, substance, human activity or condition that may cause loss of life, injury or other health impacts, property damage, loss of livelihoods and services, social and economic disruption, or environmental damage". Geoscience Australia (2010) conceptualised vulnerability as "the impact a hazard has on the people, infrastructure, and the economy". For this study, the term vulnerability has been introduced to consider the extent to which people suffer from calamities which depend on the likelihood of being exposed to hazards and their capacity to withstand them, which relates to their socio-economic circumstances (Schneiderbauer and Ehrlich 2004) rather than a response to the hazardcentric perception of disaster (Schneiderbauer and Ehrlich 2004). Exposure is defined as the number of assets such as "people, property, systems or other elements present in hazard zones that are thereby subject to potential losses" (UNISDR 2009). In this study, the term infrastructure assets include the "interrelated built, institutional and environmental systems and services" (Jollands et al. 2006).

Finally, the term adaptation capacity has been viewed as a system response to perturbations or stress that are sufficient to make fundamental changes in the system itself, shifting the system to a new state or how the system responds (Gallopin 2006; Preston and Stafford-Smith 2009); hence, may also be referred to as response capacity (Preston and Stafford-Smith 2009). This study, on the other hand, attempts to apply Eq. 3 in quantifying adaptation capacity, such that by mathematical transformation, adaptation capacity can be expressed as follows (Espada et al. 2012):

Adaptation Capacity $(\mathrm{AC})=$ Vulnerability $-($ Risk + Hazard $)$

Equation 4 has been further expressed in Equations 5 and 6.

$$
\mathrm{AC}=\text { Social Vulnerability }-(\text { Risk }+ \text { Flood Hazard })
$$


Espada et al., Using spatial modelling to develop flood risk and climate adaptation capacity metrics for assessing urban community and critical electricity infrastructure vulnerability

$$
\begin{aligned}
\mathrm{AC}= & \text { Social Vulnerability }-[(\text { Fuzzy Gamma Function } \\
& \{\text { Hazards, Physical Vulnerability, and Exposure }\}+\text { Flood Hazard })]
\end{aligned}
$$

Table 1 under Section 4.2 summarises the list of thematic layers/indicating variables used to analyse the components of flood risk and adaptation capacity.

\subsection{Topological Cluster Analysis with Self-Organising Neural Network (SONN)}

For this study, 22 initial indicating variables (5 for hazards, 13 for vulnerability, and 4 for exposure) were used in the analysis. Challenged by the selection of the most appropriate indicating variables for inclusion in the flood risk and climate adaptation capacity assessments, the Artificial Neural Network (ANN) particularly the Kohonen self-organising map (KSOM) was applied in this study. The SOM operates with the input layer where the inputs refer to the indicating variables (i.e. flood risk), neuron computation, and output layer, and a map of clustered variables as shown in Figure 3 (Mele and Crowley 2008).

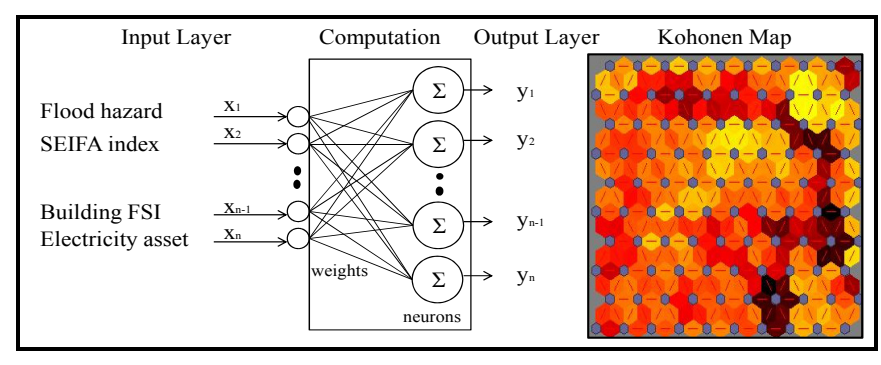

Figure 3. The conceptual self-organising neural network of the study

Table 1. The selected indicating variables from SOM analysis and corresponding Bayesian joint conditional probable weights

Processed with MATLAB version R2011b program, the standardised indicating variables (in raster formats) were structured with $907266 \times 5$ hazard, 907266 x 13 vulnerability, and 907266 × 4 exposure matrices. Utilising the Neural Network Clustering Tool, the indicating variables were grouped or clustered by similarity through the process of classifying a 2-dimension layer of 100 neurons arranged in a 10x10 hexagonal grids, trained twice with 200 epochs.

Taking flood hazard as the basis in the pair-wise comparison, seven (7) variables (i.e. biological hazard, total building value, total counts of registered businesses with turnover, revenue from small businesses, estimated period of settlement, people in need of assistance, and heritage sites) were removed from further analysis because these variables showcased dissimilar pattern from flood hazard.

\subsection{Quantification of Flood Risk and

\begin{tabular}{|c|c|c|}
\hline $\begin{array}{c}\text { Flood Risk/ } \\
\text { Adaptation Capacity } \\
\text { Component }\end{array}$ & $\begin{array}{c}\text { Selected Indicating } \\
\text { Variable }\end{array}$ & $\begin{array}{l}\text { Joint Conditional } \\
\text { Probable Weight }\end{array}$ \\
\hline \multirow[t]{4}{*}{ Hazard } & Electricity Hazard & 0.28 \\
\hline & $\begin{array}{c}\text { Building Damage } \\
\text { Hazard }\end{array}$ & 0.28 \\
\hline & Chemical Hazard & 0.31 \\
\hline & Flood Hazard & 0.13 \\
\hline \multirow[t]{6}{*}{ Social Vulnerability } & Household Income & 0.13 \\
\hline & SEIFA Index & 0.14 \\
\hline & $\begin{array}{c}\text { Emergency Services } \\
\text { Response Time }\end{array}$ & 0.16 \\
\hline & $\begin{array}{l}\text { Home and Content } \\
\text { Insurance }\end{array}$ & 0.17 \\
\hline & $\begin{array}{l}\text { Residential Tenure } \\
\text { (Rental) }\end{array}$ & 0.19 \\
\hline & $\begin{array}{c}\text { Access to Emergency } \\
\text { Services }\end{array}$ & 0.21 \\
\hline \multirow[t]{2}{*}{ Physical Vulnerability } & $\begin{array}{c}\text { Electricity Network } \\
\text { Assets } \\
\end{array}$ & 0.44 \\
\hline & $\begin{array}{l}\text { Building Floor Space } \\
\text { Index }\end{array}$ & 0.56 \\
\hline \multirow[t]{3}{*}{ Exposure } & 2011 Population & 0.20 \\
\hline & $\begin{array}{c}\text { Age }(\% \text { of } 0 \text { to } 11 \text { and } \\
\text { above } 70)\end{array}$ & 0.27 \\
\hline & $\begin{array}{l}2011 \text { Flooded } \\
\text { Properties }\end{array}$ & 0.53 \\
\hline
\end{tabular} Adaptation Capacity Metrics}

From the SONN analysis, the final 15 indicating variables which were selected to include in quantifying the flood risk and adaptation capacity metrics are summarised in Table 1.

Calculated with Bayesian joint conditional probability, the weights column from the Table indicates the weight values used in the weighted overlay operations of indicating variables of hazard, vulnerability, and exposure in ArcGIS 10. This was done to address the multi-dimensionality issue in the normative argument of equal weights. The results of applying Equations 1 and 6 are shown in Figures 4 and 5 with the flood risk metrics and adaptation capacity metrics are shown on the maps' background.

\subsubsection{Applications of Flood Risk and Adaptation Capacity Metrics}

Table 2 shows that 1306 ha (58\%) and 214 ha (9\%) of the study area were highly and very highly impacted by the January 2011 flood event, respectively. Furthermore, 896 ha (40\%) and 255 ha (11\%) were characterised of having low and very low climate adaptation capacity, respectively. 
Espada et al., Using spatial modelling to develop flood risk and climate adaptation capacity metrics for assessing urban community and critical electricity infrastructure vulnerability

Interestingly, majority of the study area (95\%) revealed negative adaptation capacity metrics $(-22$ to $<0)$ (Table 2). This significant finding would imply that vulnerability as a resource-oriented factor determines the strength or weakness of the study area; such that the generated negative values for adaptation capacity meant that the resources are not enough to increase climate resiliency of the urban community and critical infrastructures (Espada et al. 2012). The result also signifies that the resources of the community are outbalanced by 22 units taking zero as the break-even metric.

Also important to further examine are the physical and socio-economic characteristics of the study area (the remaining 5\%) that indicates positive adaptation capacity metrics ( $>0$ to 1 ) (Table 2 ). This signifies that the resources within those areas are one unit above the zero break-even or just enough to alleviate climate risk. However, extra caution should be taken into account considering that some areas are positioned in a highly favourable physical condition (e.g. higher elevation) but the socio-economic resources inhibit the adaptation to climate risk.

Adopted from Queensland Reconstruction Authority's (QRA) (2011) four phases of disaster risk reduction, the broad adaptation strategies identified in this study to increase community resiliency include mitigation, preparedness, response, and recovery.

Table 2. Summary of flood risk and adaptation capacity metrics with corresponding adaptation strategies

\begin{tabular}{|c|c|c|c|c|c|c|c|c|}
\hline \multicolumn{4}{|c|}{ Flood Risk } & \multicolumn{5}{|c|}{ Adaptation } \\
\hline Description & Metrics & $\begin{array}{c}\text { Area } \\
\text { (ha) }\end{array}$ & $\%$ & Description & $\begin{array}{c}\text { Capacity } \\
\text { Metrics }\end{array}$ & $\begin{array}{l}\text { Area } \\
\text { (ha) }\end{array}$ & $\%$ & Strategy/Measure \\
\hline Low & $1-1.01$ & 29 & 1 & High & $0-1$ & 120 & 5 & Mitigation \\
\hline Moderate & $1.01-1.14$ & 716 & 32 & Moderate & $-1.24-0$ & 996 & 44 & $\begin{array}{l}\text { Mitigation to } \\
\text { Preparedness }\end{array}$ \\
\hline High & $1.14-2.69$ & 1306 & 58 & Low & $-3.26--1.24$ & 896 & 40 & $\begin{array}{l}\text { Mitigation to } \\
\text { Response }\end{array}$ \\
\hline Very High & $2.69-20.77$ & 214 & 9 & Very Low & $-21.84--3.26$ & 255 & 11 & $\begin{array}{l}\text { Mitigation to } \\
\text { Recovery }\end{array}$ \\
\hline Total & & 2267 & 100 & & & 2267 & 100 & \\
\hline
\end{tabular}

To recap, Table 2 is the summary of a methodology identified in this study as flood risk-adaptation capacity index-adaptation strategies (FRACIAS) linkage model (Espada et al. 2012) that allows the integration of a range of spatially explicit analytical techniques used in the flood risk assessment, quantification of adaptation capacity metrics, and identification of adaptation strategies. This model addresses the issue of integrating disaster risk reduction-climate change adaptation framework, which had been treated separately for the past years (Joshi et al. 2011).

\subsubsection{Critical Electricity Network Vulnerability Assessment}

Using the results from the flood risk and adaptation capacity assessments in the electricity network vulnerability assessment, 72 highly vulnerable critical electricity assets were found to be within areas of very high flood risk and very low adaptation capacity as summarised in Table 3 . Using these highly vulnerable critical electricity assets as flag junctions (see brown square dots in Figures 4 and 5) in the Utility Network Analysis of ArcGIS 10, the connections of electricity transmission lines were

Table 3. Counts of highly vulnerable critical electricity assets

\begin{tabular}{|l|c|c|c|}
\hline $\begin{array}{c}\text { Electricity } \\
\text { Asset }\end{array}$ & $\begin{array}{c}\text { NE-NW-SW } \\
\text { Areas (No.) }\end{array}$ & $\begin{array}{c}\text { SE Area } \\
\text { (No.) }\end{array}$ & $\begin{array}{c}\text { Total } \\
\text { (No.) }\end{array}$ \\
\hline $\begin{array}{l}\text { Supply } \\
\text { substations }\end{array}$ & 14 & 0 & 14 \\
\hline $\begin{array}{l}\text { High voltage } \\
\text { switches }\end{array}$ & 30 & 7 & 37 \\
\hline $\begin{array}{l}\text { Pole } \\
\text { transformers }\end{array}$ & 10 & 11 & 21 \\
\hline Total & $\mathbf{5 4}$ & $\mathbf{1 8}$ & $\mathbf{7 2}$ \\
\hline
\end{tabular}

Table 4. Lengths of electricity network flood-disrupted connections

\begin{tabular}{|l|c|c|c|}
\hline \multirow{2}{*}{$\begin{array}{c}\text { Transmission } \\
\text { Line }\end{array}$} & \multicolumn{2}{|c|}{$\begin{array}{c}\text { Disrupted Connections } \\
\text { (linear km) }\end{array}$} & \multirow{2}{*}{$\begin{array}{c}\text { Total } \\
(\mathbf{k m})\end{array}$} \\
\cline { 2 - 3 } & $\begin{array}{c}\text { NE-NW- } \\
\text { SW Areas }\end{array}$ & SE Area & \\
\hline $110 \mathrm{kV}$ & 13.80 & 4.72 & 18.51 \\
\hline $33 \mathrm{kV}$ & 22.86 & 3.90 & 26.77 \\
\hline $11 \mathrm{kV}$ & 260.49 & 81.34 & 341.83 \\
\hline Low Voltage & 330.12 & 121.82 & 451.95 \\
\hline Total & $\mathbf{6 2 7 . 2 7}$ & $\mathbf{2 1 1 . 7 8}$ & $\mathbf{8 3 9 . 0 6}$ \\
\hline
\end{tabular}
kilometers. Results of the path analysis revealed that electricity supplies were disrupted along the $627 \mathrm{~km}$ and $212 \mathrm{~km}$ transmission lines in the North East - North West - South West (NE-NW-SW) and South East (SE) areas, respectively, due to the flood event (Table 4 and Figures 4 and 5).

During the January 2011 flood, power was disconnected in flooded and selected non-

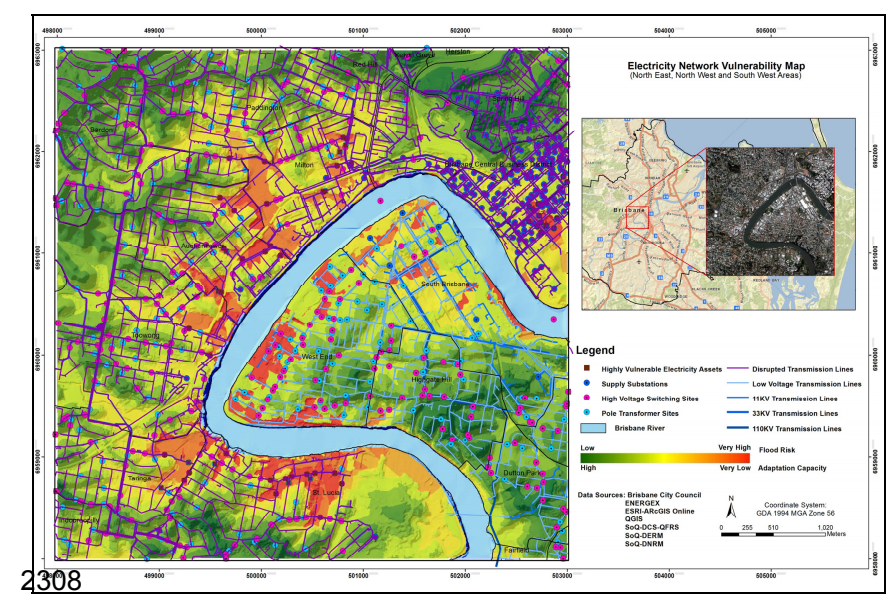

Figure 4. The generated electricity network vulnerability map on North East, North West, and South West areas 
Espada et al., Using spatial modelling to develop flood risk and climate adaptation capacity metrics for assessing urban community and critical electricity infrastructure vulnerability

flooded areas as precautionary measure (Arnold 2011, Energex 2011, QFCI 2012). Validated from the QFCI Final Report, the Milton electricity supply substation was inundated with flood waters reached $0.95 \mathrm{~m}$ above the $1 \%$ annual exceedance probability (AEP) causing damage to the substation's equipment with an estimated cost of $\$ 750,000$ (QFCI 2012).

Learning from the breakdown of some power stations (e.g. zone substations or bulk supply) due to flooding, examples of climate adaptation and resiliency strategies recommended for electricity service providers are the following (Arnold 2011, Energex 2011, Sun 2011, and QFCI 2012):

- Construction of critical electricity facilities above the defined flood level (DFL);

- Implementation of flood resilience measures such as moving critical equipment to higher locations, building bunds around substation, installing sump pumps, scaling vents and replacing all local power sockets below the DFL with appropriately rated outlets;

- Installation of connection points in the network for generators to supply electricity to non-flooded customers; and

- Electrical conduits below the applicable DFL should be sealed and

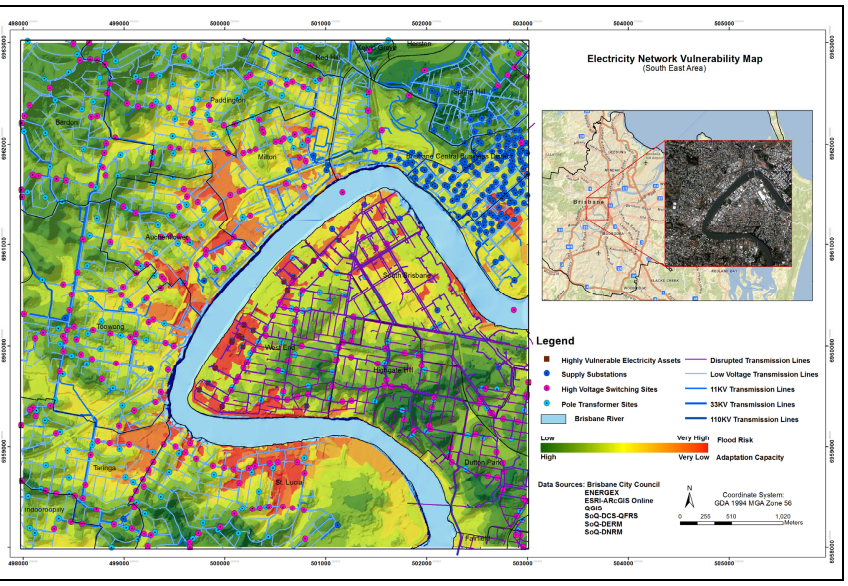

Figure 5. The generated electricity network vulnerability map on South East area water proofed to prevent floodwaters from flowing into them.

\section{CONCLUSIONS AND RECOMMENDATIONS}

As newly developed innovative technique, this study allowed the integration of complex spatially-explicit analytical methods and systematically assessed the flood risk and adaptation capacity of an urban community. This was achieved by a range of analytical methods such as 3D analysis, spatial analysis with fuzzy logic, proximity analysis, and other spatial statistics. Equally significant innovations in this study were the application of geographic interdependency modelling with spatial autocorrelation techniques such as global Moran's I and local Moran's I, topological cluster analysis with self-organising neural network, and utility network analysis.

The analyses also enabled to examine the vulnerability of critical infrastructures to climate risk and the implications once their services got disrupted. Extreme weather event caused the most damage on areas with high to very high flood risk and very low to low adaptation capacity wherein a range of critical infrastructures were found. Using this approach, power industry, for example, can explore different adaptation strategies to reduce future risk both to the power supply and the physical conditions of critical electricity infrastructure. This study may also give opportunity to urban residents to be informed on the impacts of floods to their lives, properties, in the entire community and how to better prepare for future weather risk. With emphasis on the spatial component, this study can also provide significant technical support to get the recommendations started from recently concluded enquiries on the matters arising out of the 2010/2011 floods in Queensland conducted by the Queensland Floods Commission of Inquiry (QFCI).

Finally, the following are some factors recommended to consider in the future research works:

1. Integration of hydrologic and/or hydraulic components and climate change factors in analysing flood hazards; and

2. Vulnerability assessment of water supply, roads and rails, communication, sewerage, and storm water infrastructures.

\section{ACKNOWLEDGMENTS}

The authors sincerely thanks the Australian Government - Department of Industry, Innovation, Climate Change, Science, Research and Tertiary Education (DIICCSRTE) for the Endeavour Postgraduate Award; and Brisbane City Council, ENERGEX, Queensland DERM, Queensland DNRM, and QFRS for the spatial datasets used in this study. 
Espada et al., Using spatial modelling to develop flood risk and climate adaptation capacity metrics for assessing urban community and critical electricity infrastructure vulnerability

\section{REFERENCES}

ABC News, 2011. Flood costs tipped to top \$30b. [Online] Available at: http://www.abc.net.au/news/Accessed 24 February 2013].

Arnold, C., 2011. Transcript of Proceedings. Brisbane City: Queensland Floods Commission of Inquiry.

Brisbane City Council (BCC), 2012. Brisbane Long Term Infrastructure Plan 2012-2031. , Brisbane City: Brisbane City Council.

Downing, T., 2002. Concepts of Vulnerability, AIACC Project Development Workshop: Climate Change Vulnerability and Adaptation. Trieste, Italy, Third World Avademy of Sciences.

Energex Ltd., 2011. Submission to the Holmes Inquiry into the 2010/2011 flood events, Brisbane City: Queensland Floods Commission of Inquiry.

Espada, R., Apan, A. \& McDougall, K., 2012. Spatial modelling of adaptation strategies for urban built infrastructures exposed to flood hazards. In: Queensland Surveying and Spatial Conference 2012 (QSSC 2012), 13-14 Sept 2012, Brisb. Brisbane City, Surveying and Spatial Sciences Institute.

ESRI, 2011. ArcGIS Resources. [Online] Available at: http://resources.arcgis.com/en/help/main/10.1/index.html\#//005p0000000n000000 [Accessed 2013 February 2013].

Gallopin, G., 2006. Linkages between vulnerability, resilience, and adaptive capacity. Global Environmental Change, Volume 16, pp. 293-303.

Geoscience Australia, 2010. What is vulnerability?. [Online] Available at: http://www.ga.gov.au/[Accessed 05 August 2011].

Hinkel, J., 2011. Indicators of vulnerability and adaptive capacity: Towards a clarification of the sciencepolicy interface. Global Environmental Change, Volume 21, pp. 198-208.

Hughey, E. \& Bell, H., 2010. Disaster Risk and Vulnerability, Hawaii: Pacific Disaster Center.

Jollands, N., Ruth, M., Bernier, C. \& Golubiewski, N., 2006. The climate's long-term impact on New Zealand infrastructure (CLINZI) project - A case study of Hamilton City, New Zealand. Journal of Environmental Management, Volume 83, pp. 460-477.

Joshi, K., Munsi, M. \& Joshi, A., 2011. Geoinformatics for Climate Change Adaptation and Disaster Risk Reduction. In: K. Joshi \& T. Singh, eds. Geoinformatics for Climate Change Studies. New Delhi: The Energy and Resources Institute (TERI), pp. 407-439.

McDougall, K., 2012. An assessment of the contribution of volunteered geographic information during recent natural disasters. In: A. Rajabifard \& D. Coleman, eds. Spatially enabling government, industry and citizens: research and development perspectives. Needham, MA, United States: GSDI Association Press, pp. 201-214.

Mele, P. \& Crowley, D., 2008. Application of self-organizing maps for assessing soil biological quality. Agriculture, Ecosystems and Environment, Volume 126, pp. 139-152.

Middelmann, M., 2002. Flood Risk in South East Queensland, Australia. Melbourne, Inst. of Engrs. Australia.

Mirfenderesk, H. \& Corkill, D., 2009. The need for adaptive strategic planning: Sustainable management of risk associated with climate change. Int,l Journal of Climate Change, Strategies and Mgt., 1(2), pp. 146159.

Pederson, P., Dudenhoeffer, D., Hartlet, S. \& Permann, M., 2006. Critical Infrastructure Interdependency Modelling: A Survey of U.S. and International Research, Idaho: Idaho National Laboratory.

Preston, B. \& Stafford-Smith, M., 2009. Framing Vulnerability and adaptive capacity assessment: Discussion paper. [Online] Available at: http://www.csiro.au/org/ClimateAdaptationFlagship.html.

Queensland Floods Commission of Inquiry (QFCI), 2012. Queensland Floods Commission of Inquiry Final Report, Brisbane City: Queensland Floods Commission of Inquiry.

Queensland Museum, 2011. Brisbane Flood 2011. [Online] Available at http://www.southbank.qm.qld.gov.au/ [Accessed 02 February 2012].

Queensland Reconstruction Authority (QRA), 2011. Planning for stonger, more resilient flood plains Parts 1 and 2, Brisbane City: Queensland Reconstruction Authority.

Robinson, A., 2011. Opening submission by Queensland Bulk Water Supply Authority trading as Seqwater, Brisbane City: Queensland Floods Commission of Inquiry.

Schneiderbauer, S. \& Ehrlich, D., 2004. Risk, hazard and people's vulnerability to natural hazards: A review of definitions, concepts and data, Italy: European Commission Joint Research Centre.

Sun, C., 2011. Transcript of Proceedings. Brisbane City: Queensland Floods Commission of Inquiry.

Szlafsztein, C., 2008. Adaptation to climate change and vulnerability metrics: The Index of Usefulness of Practices for Adaptation (IUPA). Tokyo, Institute for Global Environmental Strategies.

UNISDR, 2009. UNISDR Terminology on Disaster Risk Reduction. Geneva, Switzerland: United Nations International Strategy for Disaster Reduction. 